\title{
Analisis Information and Communication Technology (ICT) Literacy \\ Pengguna Aplikasi Sistem Informasi Manajemen Akademik (Studi Kasus: SIMAK Departemen SKPM)
}

\author{
Vidy Nalendra ${ }^{1}$, Irman Hermadi ${ }^{2}$, dan Ivanovich Agusta ${ }^{3}$ \\ ${ }^{1}$ Program Studi Ilmu Komputer - IPB \\ ${ }^{2}$ Departemen Ilmu Komputer - IPB \\ ${ }^{3}$ Departemen Sains Komunikasi dan Pengembangan Masyarakat - IPB
}

\begin{abstract}
Education management development, followed by the use of information technology are required by Department of Communication and Community Development Science, Faculty of Human Ecology, Bogor Agricultural University (SKPM FEMA IPB). System development is directed to the development of Academic Management Information System (MIS), which are interactive and provide information about academic. Department of Communication and Community Development Science developed an Academic Management Information System (Simak). Simak already developed but still have constraints in terms of users. User needs evaluation, ICT literacy measurement used as an approach to solving the constraints that exist for Simak users.
\end{abstract}

Keywords: Management Information System (MIS), Simak, ICT literacy,

\begin{abstract}
ABSTRAK
Pengembangan manajemen pendidikan diikuti oleh penggunaan teknologi informasi dibutuhkan oleh Departemen Sains Komunikasi dan Pengembangan Masyarakat Fakultas Ekologi Manusia Institut Pertanian Bogor (SKPM FEMA IPB). Pengembangan sistem diarahkan kepada pengembangan Manajemen Sistem Informasi Akademik (MIS), dimana interaksi dan penyediaan informasi mengenai akademik tentang SKPM, dikembangkan Sistem Informasi Manajemen Akademik (Simak). Simak selesai dikembangkan, namun tetap memiliki hambatan bagi pengguna. Pengguna membutuhkan evaluasi, perhitungan literasi ICT digunakan sebagai pendekatan untuk menyelesaikan hambatan yang masih ada bagi pengguna Simak.
\end{abstract}

Kata Kunci : Manajemen Sistem Informasi (MIS), Simak, ICT Literasi

\section{PENDAHULUAN}

\section{Latar Belakang}

Departemen Sains Komunikasi dan Pengembangan Masyarakat (Departemen SKPM), merupakan salah satu departemen yang berada di Fakultas Ekologi Manusia IPB (FEMA-IPB). Departemen SKPM dituntut untuk selalu melakukan peningkatan kualitas pembelajaran agar target dari manfaat belajar (learning outcome) dapat terpenuhi. Pengembangan manajemen pendidikan yang diikuti oleh penggunaan teknologi informasi diperlukan Departemen SKPM untuk mampu menjawab kebutuhan tersebut. Pengembangan sistem diarahkan ke pengembangan Sistem Informasi Manajemen (SIM) yang bersifat interaktif dan dikembangkan untuk menyediakan informasi seputar masalah akademik (Evaluasi Diri Departemen SKPM, 2013). Salah satu pengembangan yang saat ini 
dilakukan Departemen SKPM adalah membuat suatu Sistem Informasi dan Manajemen Akademik Departemen Sains Komunikasi dan Pengembangan Masyarakat (SIMAK SKPM).

SIMAK SKPM (selanjutnya akan disebut Simak) terpadu dengan website Departemen SKPM telah dirancang dengan berbagai ragam fitur agar dapat memadai sebagai sarana komunikasi, konsultasi, dan pengamatan oleh penggunanya yaitu dosen, tenaga kependidikan dan mahasiswa.

Simak masih mempunyai kendala dari sisi penggunanya. Kendala yang kerap terjadi bagi pengguna mahasiswa ialah kurang aktifnya mahasiswa dalam berkomunikasi melalui Simak dengan dosen pembimbingnya. Kendala yang kerap terjadi bagi dosen adalah ada beberapa dosen yang kurang atau tidak menanggapi notifikasi pesan untuk bimbingan yang diberikan oleh mahasiswa melalui Simak. Kendala yang kerap terjadi bagi tenaga kependidikan adalah lambatnya pembaruan data yang terkait dengan administrasi. Kendala-kendala tersebut membuat pengguna semakin enggan menggunakan Simak.

Berdasarkan kendala-kendala yang ada, perlu dilakukan suatu analisis pendekatan yang dapat dilakukan untuk memecahkan kendala-kendala tersebut, sehingga Simak dapat digunakan secara optimal. Pendekatan yang digunakan adalah analisis pengukuran Information and Communication Technology (ICT) literacy untuk memecahkan kendala-kendala yang ada bagi pengguna Simak.

Perkembangan teknologi informasi harus juga diikuti dengan kemampuan pengguna dalam memanfaatkan teknologi informasi tersebut. Kemampuan pengguna dalam menggunakan teknologi dapat terlihat dalam ICT literacy antara pengguna dengan sistem. Bagi dunia pendidikan tinggi ICT mempunyai banyak manfaat. Kelebihan dan kekurangan ICT untuk mahasiswa pendidikan tinggi telah diteliti oleh Perbawaningsih (2013). Teknologi baru dalam pekerjaan, pendidikan, dan kehidupan sehari-hari akan selalu berkembang pesat. Educational Testing Service (ETS) mendeskripsikan ICT literacy adalah kemampuan menggunakan teknologi digital, peralatan komunikasi dan jaringan untuk mengakses, mengelola, mengintegrasikan, mengevaluasi dan menciptakan informasi dengan tujuan untuk berfungsi dalam masyarakat pengetahuan (ETS 2002).

Tujuan penelitian ini adalah memperoleh hasil dari pengukuran ICT literacy terhadap pengguna Simak. Hasil dari pengukuran tersebut akan dijadikan rekomendasi kepada tim ICT Departemen SKPM sebagai dasar untuk pengembangan Simak.

\section{METODE}

Tahap ini melakukan identifikasi mengenai metode pengukuran ICT literacy yang akan dilakukan, pada tahap ini ialah mencari faktor-faktor yang akan dijadikan rujukan untuk menyusun kuesioner ICT literacy. Kuesioner disusun berdasarkan pengembangan dari framework Educational Testing Service (ETS) 2002, yang dikembangkan oleh California ICT Digital Literacy Assessments and Curriculum Framework (2008), yaitu : Access, Manage, Integrate, Evaluate, Create, dan Communicate. 
Berdasarkan hasil diskusi dengan pakar maka kuesioner dibagi menjadi 3 tipe dikarenakan karakteristik serta kebutuhan yang berbeda antar pengguna. Elemen ICT untuk pengguna dosen, ialah access, create, dan communicate. Elemen ICT untuk pengguna mahasiswa ialah acces, create, dan communicate. Elemen ICT untuk pengguna administrasi ialah access, manage, integrate, evaluate dan communicate.

\section{Survey Kuesioner ICT literacy}

Survey kuesioner ICT literacy akan diberikan kepada pengguna Simak. Kuesioner akan diberikan kepada responden yang terdiri atas mahasiswa, dosen, dan administrasi tenaga kependidikan yang menggunakan Simak. Penyebaran kuesioner akan dilakukan secara manual atau tatap muka

\section{Analisis ICT literacy}

Kuesioner ICT literacy bertujuan untuk mengetahui pengetahuan responden terhadap tingkat kemampuan menggunakan SIMAK. Atas dasar itu maka setiap pertanyaan dari kuesioner ICT literacy mempunyai 2 pilihan jawaban (1) Ya dan (2) Tidak

Perhitungan skor ICT literacy menggunakan rumus

$$
\frac{\sum_{i=1}^{n} Y_{i}}{n} .100
$$

Dimana $\mathrm{n}$ adalah jumlah pertanyaan yang digunakan pada kuesioner, dan $\mathrm{Yi}$ adalah jumlah responden yang menjwab YA pada kuesioner ICT. Perhitungan tersebut akan menghasilkan persentase komponen elemen ICT.

\section{HASIL DAN PEMBAHASAN}

Hasil analisis dari kemampuan ICT Literacy pengguna Simak untuk elemen access, menunjukkan bahwa pengguna Dosen, Mahasiswa, dan Tenaga administrasi sudah mengetahui tentang dan bagaimana mengumpulkan atau mengambil informasi yang diperlukan dari Simak. Dosen memperoleh skor elemen ICT sebesar 83,02\%, Mahasiswa memperoleh skor elemen ICT sebesar 72,32\%, dan administrasi memperoleh skor elemen ICT sebesar 70,83\% (Gambar $1)$.
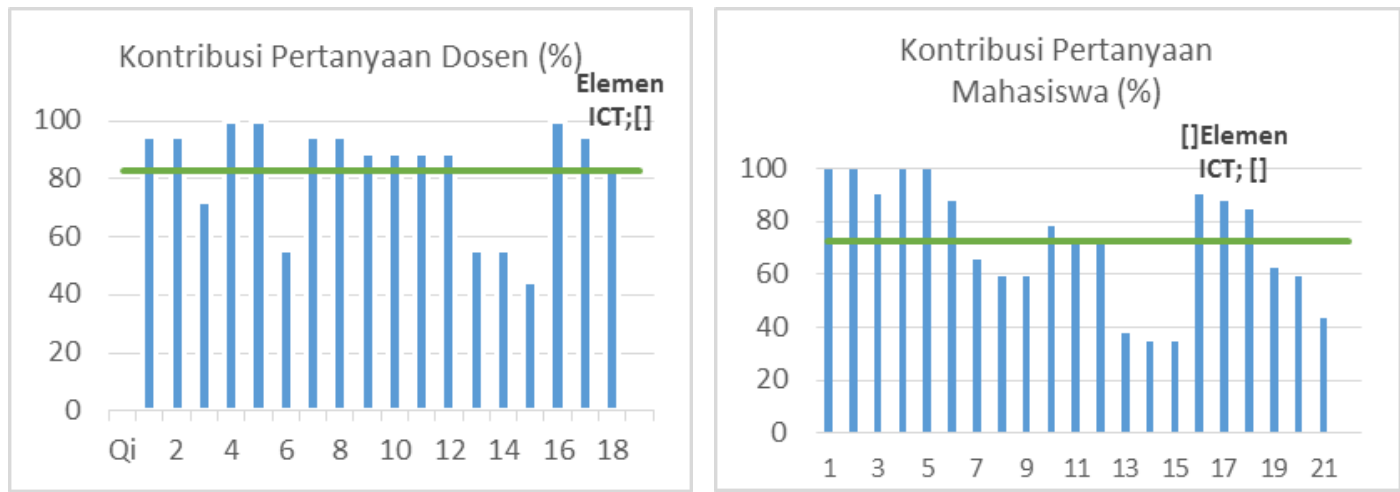


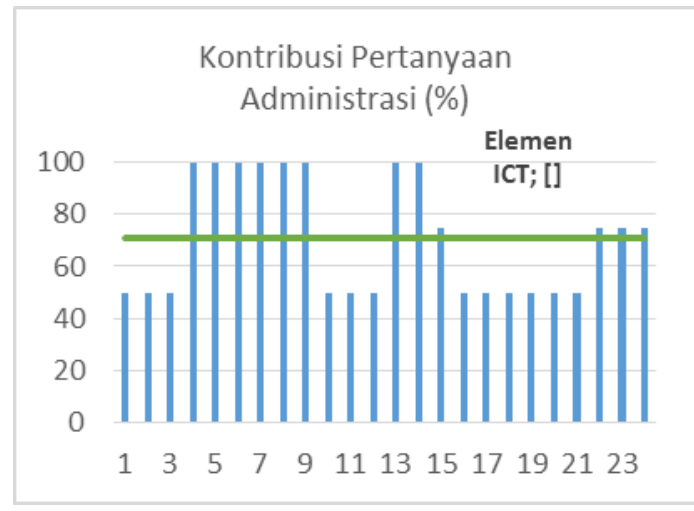

Gambar 1. Kemampuan ICT Literacy pengguna Simak untuk elemen Access

Hasil analisis dari kemampuan ICT Literacy pengguna Simak untuk elemen create, menunjukkan bahwa pengguna Dosen dan Mahasiswa sudah mengetahui tentang menghasilkan informasi dengan menyesuaikan, menerapkan, merancang, menciptakan, atau menuliskan informasi. Dosen memperoleh skor elemen ICT sebesar 83,33\%, Mahasiswa memperoleh skor elemen ICT sebesar 77,08\%, (Gambar 2)
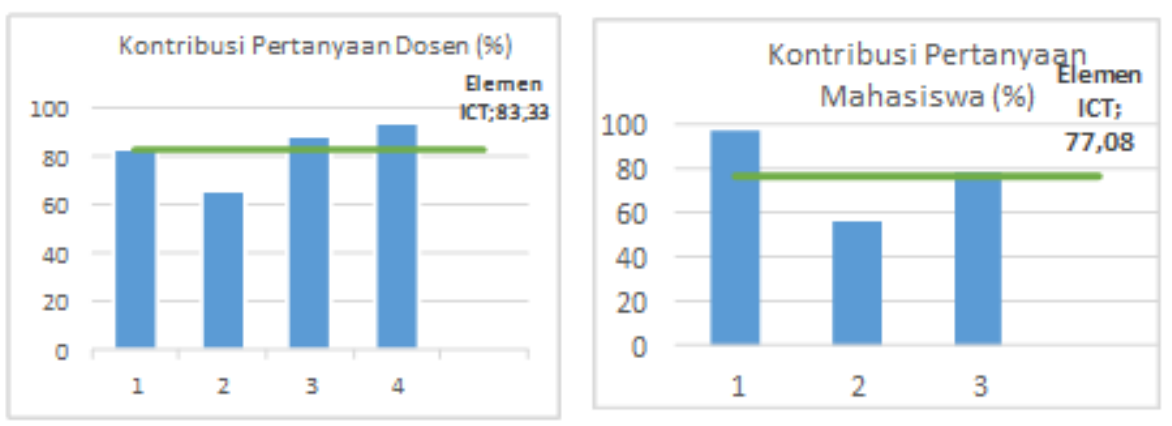

Gambar 2. Kemampuan ICT Literacy pengguna Simak untuk elemen Create

Hasil analisis dari kemampuan ICT Literacy pengguna Simak untuk elemen Manage, menunjukkan bahwa pengguna Tenaga administrasi sudah mengetahui tentang menghasilkan informasi dengan menyesuaikan, menerapkan, merancang, menciptakan, atau menuliskan informasi dari Simak. Tenaga Administrasi memperoleh skor elemen ICT sebesar 62,5\% (Gambar 3).

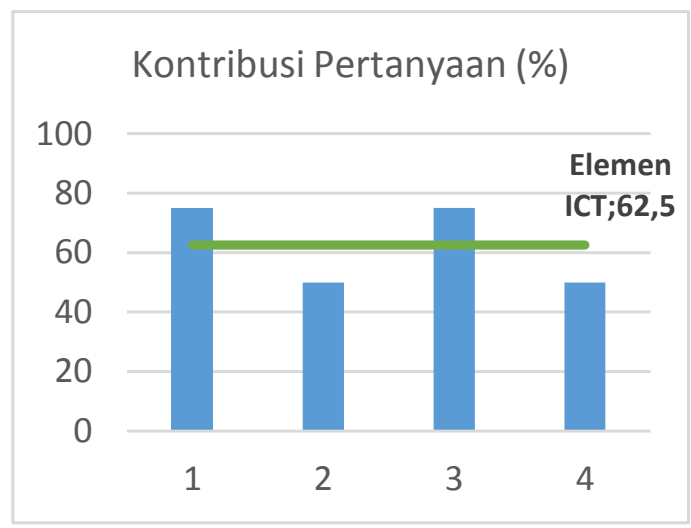

Gambar 3. Kemampuan ICT Literacy pengguna Simak untuk elemen Manage 
Hasil analisis dari kemampuan ICT Literacy pengguna Simak untuk elemen Evaluate, menunjukkan bahwa pengguna Tenaga administrasi sudah mengetahui tentang membuat penilaian atas kualitas, relevansi , kegunaan, atau efisiensi informasi dari Simak. Tenaga Administrasi memperoleh skor elemen ICT sebesar $55 \%$ (Gambar 4).

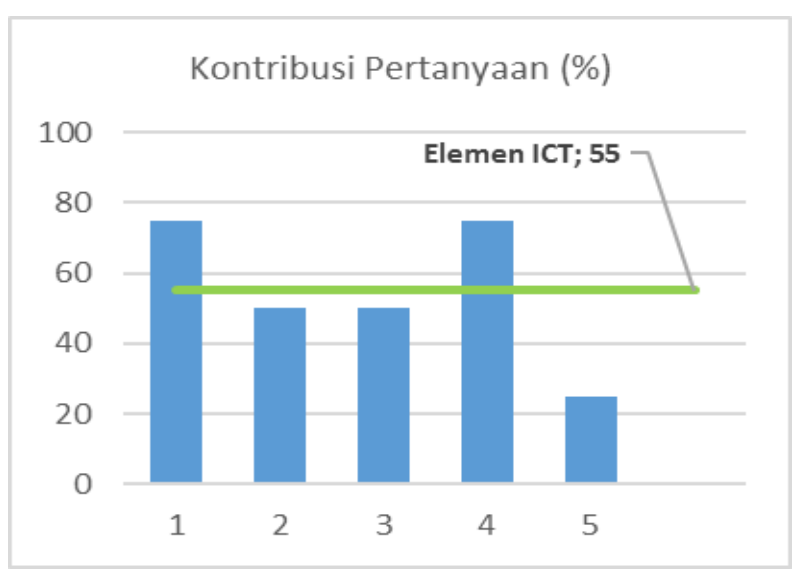

Gambar 4. Kemampuan ICT Literacy pengguna Simak untuk elemen Evaluate

Hasil analisis dari kemampuan ICT Literacy pengguna Simak untuk elemen Integrate, menunjukkan bahwa pengguna Tenaga administrasi masih perlu ditingkatkan kemampuan ICT literate untuk memahami dalam menafsirkan dan mewakili informasi (meringkas, membandingkan, dan mengkontraskan) melalui Simak. Tenaga Administrasi memperoleh skor elemen ICT sebesar 37,5\% (Gambar 5).

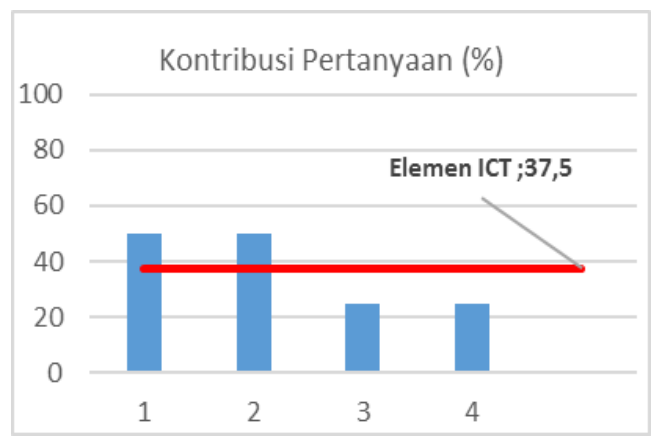

Gambar 5. Kemampuan ICT Literacy pengguna Simak untuk elemen Integrate

Rendahnya kemampuan ICT literate tenaga administrasi untuk elemen Integrate dapat ditingkatkan melalui pelatihan-pelatihan yang mendukung tenaga administrasi dalam menyusun laporan berdasarkan data-data yang diperoleh dari Simak. Pelatihan yang diperlukan oleh tenaga administrasi, ialah pelatihan penggunaan Simak

Pelatihan pengolahan dan penyajian data dari Simak, seperti pengolahan data-data kemahasiswaan untuk keperluan akreditasi, Sistem Penjaminan Mutu Internal (SPMI). Hasil analisis dari kemampuan ICT Literacy pengguna Simak untuk elemen Communicate, menunjukkan bahwa pengguna Dosen, Mahasiswa dan Tenaga administrasi perlu meningkatkan kemampuan ICT literate terkait 
tentang mengkomunikasikan informasi persuasif untuk memenuhi kebutuhan berbagai khalayak melalui Simak. Dosen memperoleh skor elemen ICT sebesar 45,83\%, Mahasiswa memperoleh skor elemen ICT sebesar $45 \%$, dan Tenaga Administrasi memperoleh skor elemen ICT sebesar 41,67\% (Gambar 6).

Rendahnya kemampuan ICT literate dosen, mahasiswa, dan tenaga administrasi untuk elemen Communicate dikarenakan fitur pengiriman pesan instan antar pengguna pada Simak jarang digunakan. Pengguna lebih sering menggunakan aplikasi pengiriman pesan instan yang lebih populer digunakan (misal: WhatsApp, BlackBerry Messenger, dan Line
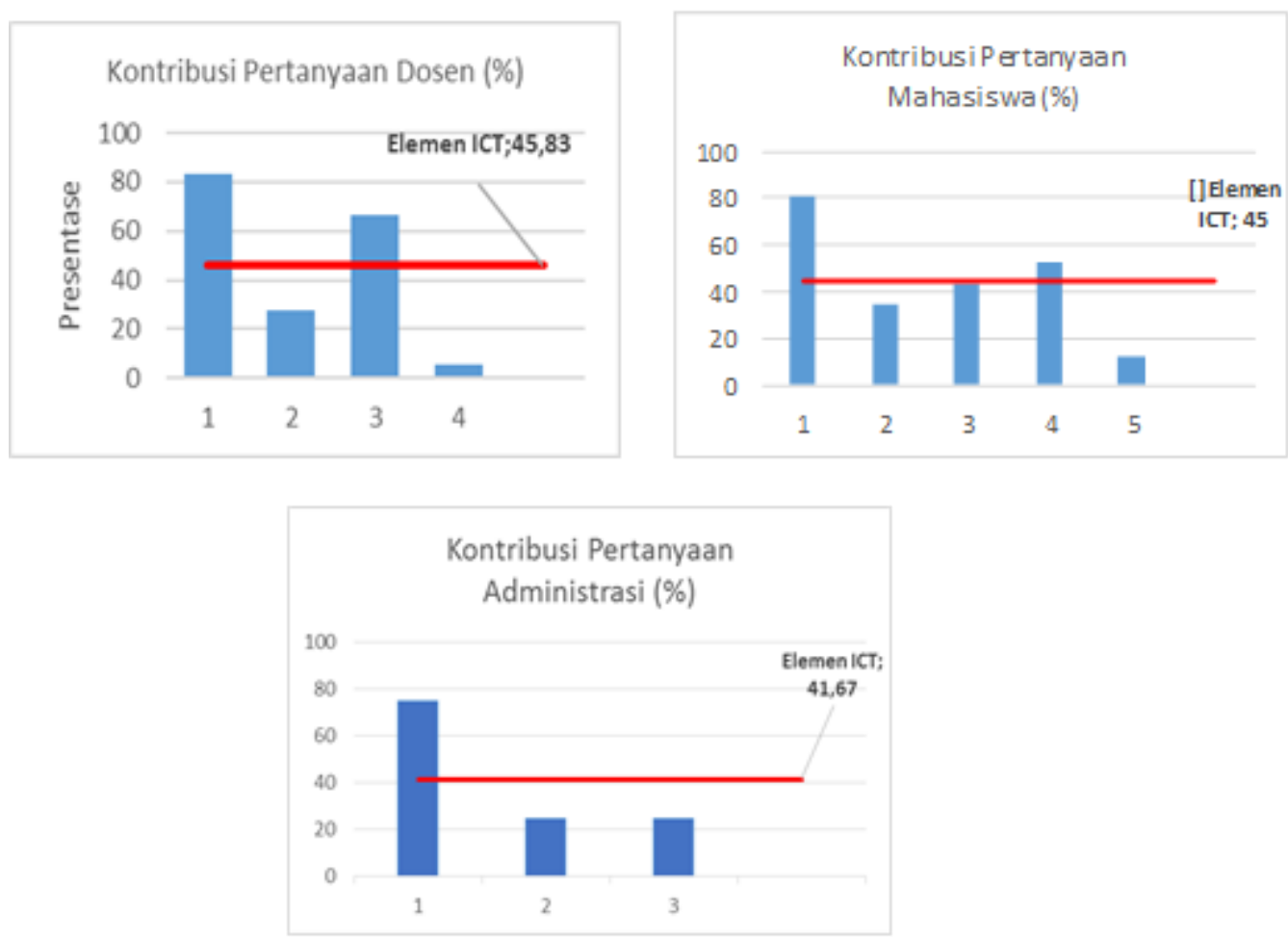

Gambar 6. Kemampuan ICT Literacy pengguna Simak untuk elemen Communicate

\section{SIMPULAN}

Mayoritas pengguna Simak sudah mempunyai tingkat pemahaman ICT yang baik. Dosen mempunyai kemampuan elemen ICT yang baik untuk elemen access dan create, sedangkan untuk elemen communicate masih perlu ditingkatkan pemahamannya. Mahasiswa mempunyai kemampuan elemen ICT yang baik untuk elemen access dan create, sedangkan untuk elemen communicate masih perlu ditingkatkan pemahamannya. Administrasi mempunyai kemampuan elemen ICT yang baik untuk elemen access, manage, dan evaluate, sedangkan untuk elemen integrate dan communicate masih perlu ditingkatkan pemahamannya.

Pelatihan kegunaan dan olah data Simak diperlukan oleh tenaga administrasi untuk meningkatkan kemampuan ICT literacy yang terkait dengan elemen integrate. Fitur pengiriman pesan instan antar pengguna harus dikembangkan, sehingga pengguna Simak dapat lebih aktif menggunakan fitur 
tersebut. Pengembangan fitur pengiriman pesan instan dapat meningkatkan kemampuan ICT literacy yang terkait dengan elemen communicate.

\section{DAFTAR PUSTAKA}

Departemen SKPM FEMA - IPB. 2013. Evaluasi Diri AKREDITASI SKPM 2013. Bogor: Departemen Sains Komunikasi dan Pengembangan Masyarakat FEMA - IPB.

California Emerging Technology Fund.2008.California ICT Digital Literacy Assessments and Curriculum Framework [Internet].[diunduh 24 Maret 2014]. http://www.ictliteracy.info/rf.pdf/California ICT Assessments and Curriculum Framework.pdf

Educational Testing Service. 2002. Digital Transformation A Framework for ICT Literacy. [Internet] [diunduh $2014 \quad$ Mei 02 ] http://www.ets.org/Media/Tests/Information and Communication Techn ology Literacy/ictreport.pdf

Perbawaningsih, Yadi. (2013). Plus Minus of ICT Usage in Higher Education Students. Procedia - Social and Behavioral Sciences 103. $717-724$ 